\title{
依托微课 让数学课“活”起来
}

\author{
张黎辉 \\ 都垶市丛台区学步桥小学 \\ DOI:10.32629/jief.v2i6.1079
}

[摘 要] 随着素质教育改革的全面深入发展, 我国义务教育事业逐渐面向新数字化、现代化, 其中, 最具有代表性的便是网络微棵, 很大程 度上冲击着传统小学教学体系, 也被广泛应用于小学各个学科实际教学过程中。因此, 在此背景之下, 为进一步有效地促进教育改革, 文章 主要就小学数学微课的教学设计展开了系统的研究。

[关键词] 小学; 数学; 微课

中图分类号：G633.6 文献标识码：A

学生步入小学阶段, 由于还未形成良好的学习习惯, 缺乏足够的认 知水平, 这就需要小学数学教师为学生创设丰富多彩的教学活动来提升 学生的学习兴趣。在当前新课改模式的影响下, 教师要充分尊重学生的 主体性地位, 通过在小学数学课堂中充分应用微课这一新型教学模式, 逐步改变传统教学模式带来的不足和弊端。在当前新形势下, 微课这一 新型的教学模式已经成为新课改中的重点内容。

\section{1 利用微课, 提高课堂教学的趣味性}

在教学的过程中, 如果一味采取传统的教学方式, 对于学生来说, 有着一定的限制, 课堂也缺乏一定的趣味性。因此在课堂的教学过程中, 教师可以通过利用微课技术, 将数学知识点内容以图片、视频、动画等 多种多样的形式展示给学生, 让学生得到更多的体验, 从而让学生更好 地投入到教学过程中，激发学生的学习积极性。

例如在学习《认识人民币》这一教学内容时, 教师可以在课堂上, 利用微课, 为学生创设一定的教学情境, 让学生更好地投入到教学中, 提高学习的学习兴趣。教师可以利用微课, 为学生讲述人民币的发展史, 扩展学生们的知识面, 让学生在课堂上学习到更多的知识内容, 丰富学 生的课堂学习体验。

\section{2 使用微课丰富教学内容}

如今, 微课教学属于新型教学形式, 其已在小学时期的数学教学当 中得到广泛运用。因为微课具有的主体化、碎片化以及多样化这些特征 可以完美契合儿童的心理结构以及年龄特征, 所以可以在小学教学之中 发挥出微课教学具有的优势。课堂作为当前学生学习的主要场所, 教师 在实际教学过程中, 需要更好地提升课堂教学效率, 争取让学生在课堂 内深入理解所学内容, 提升学习质量。但在实际的数学知识教学中存在 一些理解难度大的问题, 教师可以借助微课更好地完成教学。例如, 讲 解 “线与角” 的相关内容时, 如果教师一味地向学生灌输基础知识点, 学生很难有效理解角的概念。教师可以使用微课教学模式, 借助视频展 示线与角的相关内容, 使整个知识讲解过程呈现动态变化。除此之外, 教师在实际教学过程中也可以合理引入一些生活中的实际案例, 可以展 示一些生活中关于线与角的实际事物, 使知识讲解更加生动形象, 这样 学生对知识的印象也会更加深刻, 学习效率自然明显提升。

\section{3 充分发挥学生的感官能动性, 充分调动各个感官}

微课是教师根据学生对教学知识的掌握情况、学习能力等精心制作 完成, 在微课视频出现后, 学生能够在不同地点通过手机、电脑等进行 学习, 并完成一定作业。为了能够更好调动学生的主动性, 教师教学期 间应该及时设置相关问题, 并对学生进行一定引导, 让学生充分发挥自 己的嘴、手等作用, 让学生能够准确捕捉教师的教学进度。这样的一个 过程, 在最大程度上调动起学生学习的主动性与主导性。

\section{4 结合各种微课资源, 优化数学教学模式}

在数学课程中教师进行微课教学, 可以结合信息技术搜集各种教学
资源, 制作各种形式的微课课件, 优化数学教学模式, 真正将数学课堂 交给学生, 学生可以自己进行数学思考, 也可以利用微课平台寻找各种 数学知识, 从而有效的对学生进行各种数学知识的教育, 培养学生的自 主学习能力，促进学生核心素养的培养。

例如, 在学习人教版小学数学课程中关于 “三角形面积的讲解” 的 知识时, 教师可以先让学生对数学教材进行预习, 让学生可以通过微课 对三角形的高与底进行初步的学习, 学生可以自己形成对知识的理解和 看法, 并将自己不懂的地方进行学习和把握, 在课堂上进行针对性的学 习, 也可以通过提问的方式进行对知识的学习, 从而开展对学生的数学 教育。

\section{5 微课在课后复习环节中的应用}

古人云 “温故而知新, 可以为师矣”, 由此可见课后巩固对于学习的 重要性。数学作为应用型学科, 其存在的根本意义就是运用数学技能解 决问题, 因此学生在数学学习中要 “理论与实践” 并重。小学生的学习 既需要教师和家长共同监督和辅导, 也需要自身的自觉性。教师可将微 课巩固视频上传至网络, 要求学生回家观看, 并完成视频中的巩固练习。 在巩固视频的设计中, 教师要将知识点与练习相互穿插, 方便学生在知 识点巩固后快速练习。例如在《分数乘法》的课后巩固视频中, 教师首 先回顾分数的基本组成 (分子、分母), 再重点回顾分数的乘除运算和计 算注意事项, 紧跟着视频中给出难度层次分明的分数计算题令学生巩固 计算, 最后展现分数在生活中的实际应用, 提高学生的分数实际应用能 力。为督促学生认真巩固, 教师可要求学生提交视频习题的书面作业并 加以批改分析, 并在下一节的微课视频中对学生作业中出现的错误加以 强调, 在达到教学目标的同时又能培养学生良好的学习习惯。

随着新课改的发展, 将微课应用在现代化教学中已经成为一种新的 趋势, 微课是信息时代教学工具的延伸, 是对学科知识点进行有机整合 的资源载体。在小学数学课堂中引入微课进行教学, 可以帮助学生加深 对于数学内容的理解, 提高自主学习的积极性, 促进教学的发展。微课 的设计与应用是紧密相关的, 好的微课既要具备清晰的设计思路, 又需 要具备良好的应用效果, 使其更好地满足当前小学数学教学的需求。要 结合小学数学的具体内容, 自觉地将微课进行灵活的应用, 让学生掌握 到相关的数学思想的实质, 为后续的数学学习打下良好的基础。要不断 地对小学生的数学学习进行探索, 实现从 “知识理解” 到 “动力机制” 的转变, 帮助学生更好的主动学习。

\section{[参考文献]}

[1]石蔚练.走出小学数学课改误区[J].家教世界,2020(Z3):88.

[2]肖艳萍. 对于小学数学课后作业布置的几点思考[J].中国校外教 育,2020(21):42.

[3] 李佳梅. 小学数学课有效提问之我见[N]. 云南经济日 报,2020-07-27(B02) 